\title{
Cerebrovascular Lesions in Experimental Renal Hypertensive Rats
}

\author{
Hideo Ueda, M.D., Hiroshi Matsuo, M.D., \\ and Hisakazu Yasuda, M.D.
}

SUMmary

With constriction of left renal arteries of 193 rats in different degrees and either extirpation or infarction of right kindeys, four different elevation patterns of blood pressure were followed.

(1) Macro- and microscopically, these rats developed 6 different cerebrovascular lesions as follows; single massive cerebral hemorrhage, multiple punctate hemorrhage, microscopic hemorrhage, fibrinoid necrosis, cerebral softening and plasmatic imbibition.

(2) Rats which developed single massive hemorrhage died unexpectedly in the early stage of experiment with moderate degree of constriction, while those which developed multiple punctate hemorrhage became temporarily hyperirritable.

(3) Single massive hemorrhage, multiple punctate hemorrhage and fibrinoid necrosis were found almost exclusively in the cerebral cortical area, while $30-40 \%$ of microscopic hemorrhage, cerebral softening and plasmatic imbibition were also found in the basal ganglia.

(4) Loosely constricted groups with low rate of increase and also low maximum of blood pressure showed high incidences of microscopic hemorrhage, plasmatic imbibition and cerebral softening and none of macroscopic hemorrhage or fibrinoid necrosis. Moderately constricted groups with both a high rate of increase and also a high maximum of blood pressure developed more single massive cerebral hemorrhage than multiple punctate hemorrhage and fibrinoid necrosis and cerebral softening in about half of the cases but few of microscopic hemorrhage and plasmatic imbibition. Severely constricted groups and group of contralateral renal infarction caused more multiple punctate hemorrhage than single massive hemorrhage and the latter of which showed fibrinoid necrosis, cerebral softening and microscopic hemorrhage in about half of the cases.

(5) Microscopic hemorrhage and plasmatic imbibition were maximal in appearances at the moderate degree of hypertension and subsided abruptly later on, while cerebral softening and multiple punctate hemorrhage were the more frequent as the blood pressure rose higher. Fibrinoid necrosis and single massive hemorrhage showed their peak appearances around the time when the rate of increase of blood pressure was maximal.

In summary, there are three types of cerebral hemorrhage in Goldblatt type hypertensive rats and they seemed to be pathogenetically

From the Second Department of Internal Medicine, Faculty of Medicine, University of Tokyo, Tokyo.

Received for publication September 15, 1967. 
different each other.

\section{Additional Indexing Words :}

Single massive cerebral hemorrhage Multiple punctate cerebral hemorrhage Microscopic cerebral hemorrhage Fibrinoid necrosis Cerebral softening Plasmatic imbibition Elevation pattern of blood pressure

$\mathrm{H}^{\mathrm{I}}$ IGH blood pressure and cerebral arteriolonecrosis have been thought to be the main pathogenetical factors of human cerebral hemorrhage, since it occurs mostly in hypertensive subjects whose cerebral small arteries often show necrotic lesions.

Since 1938 , when $H$. Goldblatt ${ }^{7}$ reported that similar vascular lesions had been induced in experimental hypertensive dogs by constricting the renal arteries, many investigators have tried to elucidate the pathogenesis of the experimental vascular lesions and have postulated the participation of mechanical (increase of intraluminal pressure) and/or humoral factors (" angiotoxic substance").

These reports, however, are mainly based on the results of extracranial vascular lesions such as mesenteric, cardiac or renal arteries or arterioles and few are concerned with the time-factor analysis of pressure effect or clinical and/or pathological comparative study of different cerebrovascular lesions such as hemorrhage, softening, angionecrosis and hypertensive encephalopathy in a large numbers of experimental animals.

Therefore, the authors made the rats hypertensive by constricting their renal arteries in different degrees with silver ribbon-made clamps of different sizes and shapes, while recording different elevation patterns of blood pressure. As expected, this caused different cerebrovascular lesions.

With this approach, the authors could demonstrate high incidences of cerebral macro- and microscopic hemorrhage, cerebral softening, fibrinoid necrosis of arterioles. These results were evaluated from the following standpoints ; clinical course, elevation patterns of blood pressure, localization and frequency of the lesions, time-factor analysis.

\section{METHOD}

One hundred and ninety-three female rats of Wistar strain, weighing 150 $230 \mathrm{Gm}$., were divided into 7 groups according to the operative procedures as shown in Table I. They were fed on Oriental chow and given tap water ad libtum. Under light ether anesthesia, left lumbar incisions were made on the rats to isolate the left renal arteries which were in various degrees constricted with silver ribbon-made clamps of $0.1 \mathrm{~mm}$. in thickness and $1.6 \mathrm{~mm}$. in width. The clamp was secured and held from opening up by an additional clasp hooked around its 
Table I. Method

\begin{tabular}{|c|c|c|c|c|}
\hline \multirow{2}{*}{ Group } & \multirow{2}{*}{$\begin{array}{c}\text { Numbers } \\
\text { of Rats }\end{array}$} & \multicolumn{3}{|c|}{ Method } \\
\hline & & \multicolumn{2}{|c|}{ Left Kidney } & Right Kidney \\
\hline 1 & 43 & {$[=w$} & $\begin{array}{c}\text { widh (mm.thickness } \\
1.6 \\
\end{array}$ & \multirow{6}{*}{ Nephrectomy } \\
\hline 2 & 49 & $\square=$ & 0.3 & \\
\hline 3 & 45 & 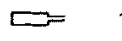 & 1.0 & \\
\hline 4 & 15 & $\mathrm{O}$ & $\begin{array}{l}\text { inner dianteter (mni.) } \\
0.81\end{array}$ & \\
\hline 5 & 20 & $c=$ & 0.50 & \\
\hline 6 & 10 & $c=$ & 0.35 & \\
\hline 7 & 11 & $\mathrm{C}=$ & 0.50 & Infarction \\
\hline & 193 & & & \\
\hline
\end{tabular}

handles. The right kidney was either extirpated or infarcted (group 7 only). Blood pressure and body weight were measured once or twice a week. Systolic blood pressure was determined by Microphonic Cuff Method ${ }^{5)}$ without anesthesia after $10 \mathrm{~min}$. exposure to heat of $45^{\circ} \mathrm{C}$. Rats were sacrificed at regular interval after constriction. The serum urea nitrogen was estimated with Unigraph at sacrifice. The brains were macro- and microscopically examined with hematoxylineeosin, elastica-van Gieson, azan-Mallory and PAS stains. ${ }^{8)}$ One brain of massive hemorrhage was cut in serial sections for histological examinations. Experiment was terminated in about 10 weeks after constriction.

\section{Results}

I. Blood pressure

(1) Maximal blood pressure

Fig. 1 illustrates the time-course of average blood pressure of each experimental group. Those of group 3,5 and 7 reached up to $200 \mathrm{~mm}$. $\mathrm{Hg}$, while those of group 1 and 2 at most stayed $150-160 \mathrm{~mm} . \mathrm{Hg}$ and that of group 4 remaind around $130-140 \mathrm{~mm} . \mathrm{Hg}$.

(2) Time-course of blood pressure elevation (Table II)

Table II shows the percentages of rats with blood pressure above 150 and $200 \mathrm{~mm} . \mathrm{Hg}$ at the early (10-14 days after constriction), middle (30 days) and late (50-70 days) stages of experiment. Sixty-one \% of group 3 and $78 \%$ of group 5 were already above $150 \mathrm{~mm} . \mathrm{Hg}$ and some $20 \%$ of both groups above $200 \mathrm{~mm} . \mathrm{Hg}$ at the early stage, while $12 \%$ and $6 \%$ of group 7 (contralateral renal infarction) were above 150 and $200 \mathrm{~mm} . \mathrm{Hg}$ at the stage although the group equaled the former 2 groups in the increase of blood pressure after the middle stage of experiment. This group showed marked fluctuations of pressure curve. No rat of group 1 and 4 was above $200 \mathrm{~mm} . \mathrm{Hg}$ throughout 


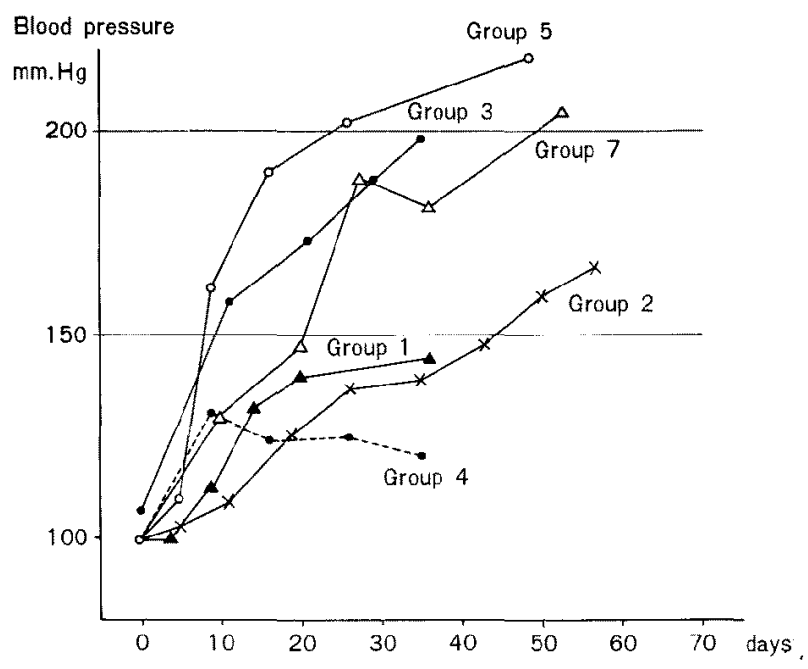

Fig. 1. Ghange of average blood pressure.

Table II. Percentages of Rats with Blood Pressure Above 150 and $200 \mathrm{~mm} . \mathrm{Hg}$ at the Early, Middle and Late Stages of Experiment

\begin{tabular}{|c|c|c|c|c|c|c|}
\hline $\begin{array}{c}\begin{array}{c}\text { Postoperative Period } \\
\text { (days) }\end{array} \\
\text { Blood }\end{array}$ & \multicolumn{2}{|c|}{$10-14$} & \multicolumn{2}{|c|}{30} & \multicolumn{2}{|c|}{$50-70$} \\
\hline $\begin{array}{cc}\text { Pressure } & \mathrm{mm} . \mathrm{Hg} \\
\text { Group } & \\
\end{array}$ & $>150$ & $>200$ & $>150$ & $>200$ & $>150$ & $>200$ \\
\hline 1 & $13 \%$ & $0 \%$ & $30 \%$ & $0 \%$ & $8 \%$ & $0 \%$ \\
\hline 2 & 11 & 0 & 30 & 5 & 58 & 16 \\
\hline 3 & 61 & 21 & 93 & 40 & 84 & 67 \\
\hline 4 & 6 & 0 & 11 & 0 & 0 & 0 \\
\hline 5 & 78 & 17 & 100 & 50 & - & - \\
\hline 6 & - & - & - & - & - & - \\
\hline 7 & 12 & 6 & 92 & 46 & 100 & 78 \\
\hline
\end{tabular}

the experiment. Five and $16 \%$ of group 2 were above $200 \mathrm{~mm} . \mathrm{Hg}$ in the middle and late stages of experiment.

(3) Rate of increase of blood pressure

Initial 9-11 days' elevation of blood pressure differs significantly (Table III) ; maximam was groups 3 and 5, followed by groups 4 and 7 and then groups 1 and 2.

Seven experimental groups can be classified into four according to the degree of rate of increase and maximum of blood pressure (Table IV). 
Table III.

Initial Rate of Increase of Blood

Pressure

\begin{tabular}{c|c}
\hline Group & $\begin{array}{c}\text { Rate of } \\
\text { Increase of } \\
\text { Blood Pressure } \\
\text { (mm.Hg/day) }\end{array}$ \\
\hline 1 & 1.4 \\
2 & 1.0 \\
3 & 4.9 \\
4 & 3.4 \\
5 & 6.9 \\
6 & $?$ \\
7 & 3.1
\end{tabular}

Table IV.

Four Different Elevation Patterns of Blood Pressure

\begin{tabular}{|c|c|c|}
\hline $\begin{array}{c}\text { Maximal } \\
\text { Blood Pressure }\end{array}$ & $\begin{array}{c}\text { Rate of } \\
\text { Increase of } \\
\text { Blood Pressure }\end{array}$ & Group \\
\hline moderate & low & 1,2 \\
\hline low & moderate & 4 \\
\hline high & moderate & 7 \\
\hline high & high & 3,5 \\
\hline
\end{tabular}

Table V. Average Terminal Blood Urea Nitrogen

\begin{tabular}{c|c}
\hline Group & $\begin{array}{c}\text { Blood Urea } \\
\text { Nitrogen } \\
\text { mg./100 ml. }\end{array}$ \\
\hline 1 & 22 \\
2 & 26 \\
3 & 43 \\
4 & 28 \\
5 & 36 \\
6 & 130 \\
7 & 37
\end{tabular}

II. Body weight (Fig. 2)

The change of average body weight of each group did not differ significantly.

III. Blood urea nitrogen (Table V)

Average terminal blood urea nitrogen of each group is shown. That of severely constricted group 6 was $130 \mathrm{mg} . \%$, the highest value among the groups. Besides, $43 \mathrm{mg} . \%$ of group 3 was the maximum.

IV. Clinical course

Group 6 with high terminal blood urea nitrogen became ill the next day of nephrectomy; crouching with the hair rolled up, anorectic and mostly dying by the second postoperative day. In groups 3,5 and 7 , there appeared in the early stage of experiment a rat which was found to be clinically healthy the day before and dead or nearly dead early the next morning. Autopsy revealed a single massive cerebral hemorrhage in all 21 rats.

On the other hand, a little later there appeared a rat which became clinically hyperirritable to outer stimuli ; jumping around, rearing up, foaming at the mouth and twitching all over the body. Some rats were monoplegic temporarily. The course of the condition was often progressively worse, but there were some rats which became normal afterward. Autopsy showed cerebral edema associated with punctate multiple hemorrhage in $63 \%$ (19 cases) of these rats.

V. Macro- and microscopic findings

In the experiment, the authors could classify 6 different cerebrovascular lesions in the macro- and microscopic studies.

(1) Single massive cerebral hemorrhage (Fig. 3) 


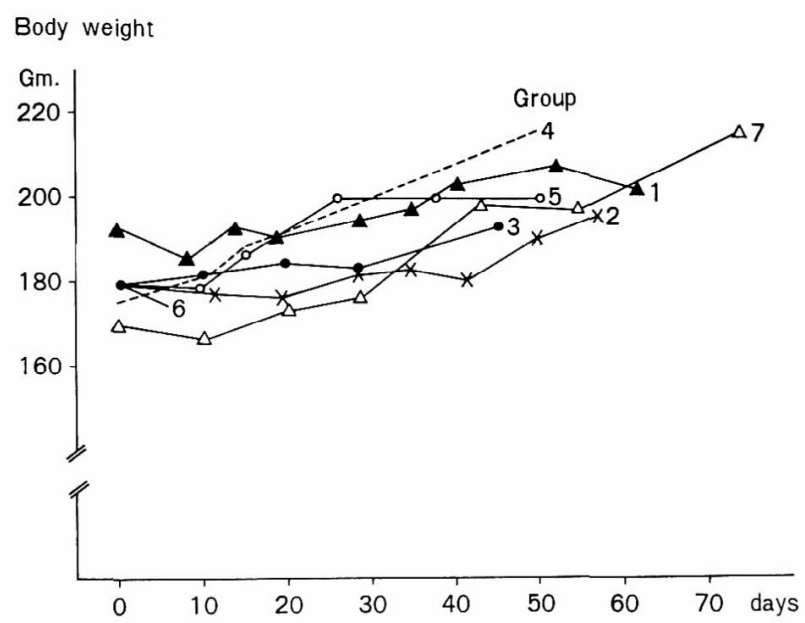

Fig. 2. Ghange of average body weight.

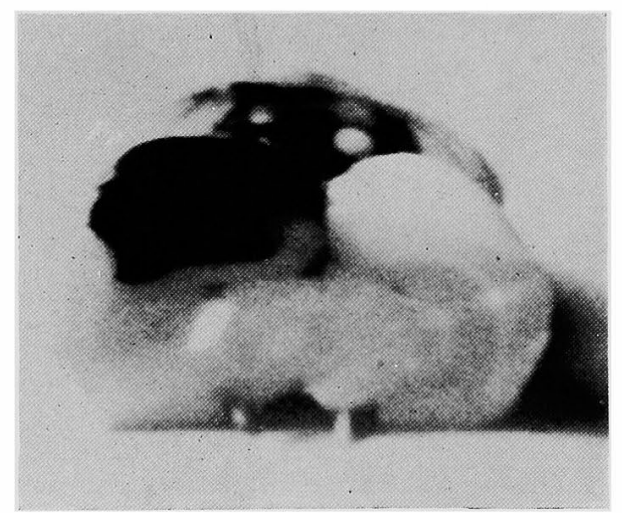

Fig. 3. Single massive hemorrhage.

This is a intra-cerebral hemorrhage, measuring greater than $3 \mathrm{~mm} .^{*}$ in its largest diameter, found mostly (19 of 21 cases) in the cerebral cortical-subcortical area of either side with equal frequency. No cerebral edema was noted.

(2) Multiple punctate cerebral hemorrhage (Fig. 4)

One to several punctate hemorrhages, measuring less than $3 \mathrm{~mm}$. in diameter, were associated with cerebral edema. All (19 cases) were found in cortical-subcortical area.

* Byrom reported that "major hemorrhage" of his hypertensive encephalopathy rat measured 2-3 mm. in diameter. 


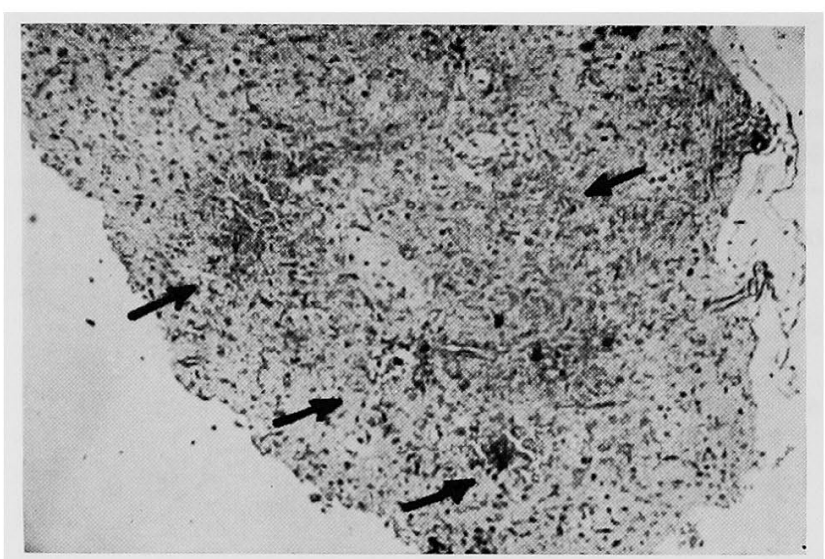

Fig. 4. Multiple punctate hemorrhage.

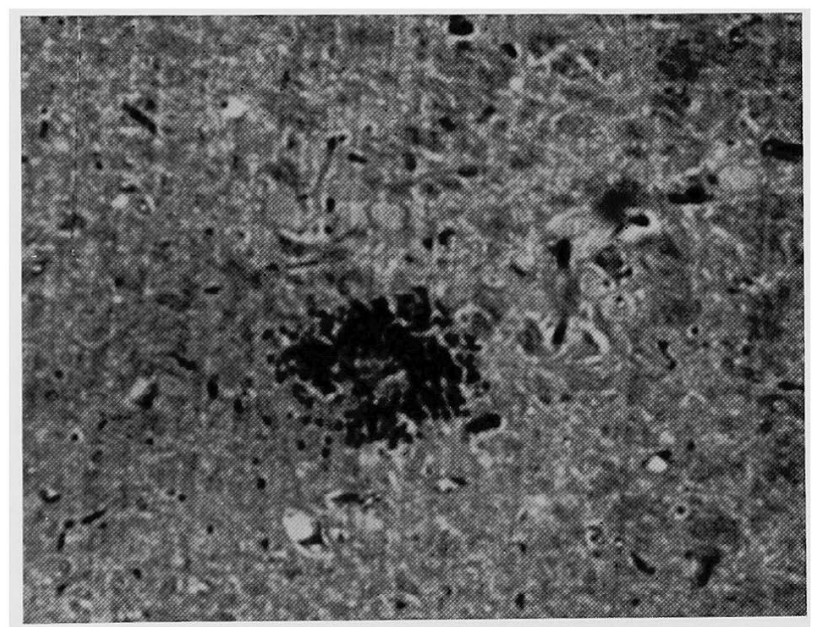

Fig. 5. Microscopic hemorrhage.

(3) Microscopic hemorrhage (Fig. 5)

A tiny hemorrhage, only found under microscope, extending about $50 \mu$. in diameter with small vessels inside which appear normal on the routine staining examinations. Sixty-two \% (24/39) were found in the corticalsubcortical area, and $38 \%$ were in the basal ganglia.

(4) Fibrinoid necrosis (Fig. 6)

This is characterized by the deposition of homogenous material in subintimal to medial layers of cortical-subcortical (23/30) and occasionally of basal arterioles, measuring $50-100 \mu$. in diameter. Tinctorially this material stains eosinophilic on hematoxyline-eosin stain, positive for PAS and red on azanMallory's. Elastic lamellae disrupt or even disappear in this part of the 


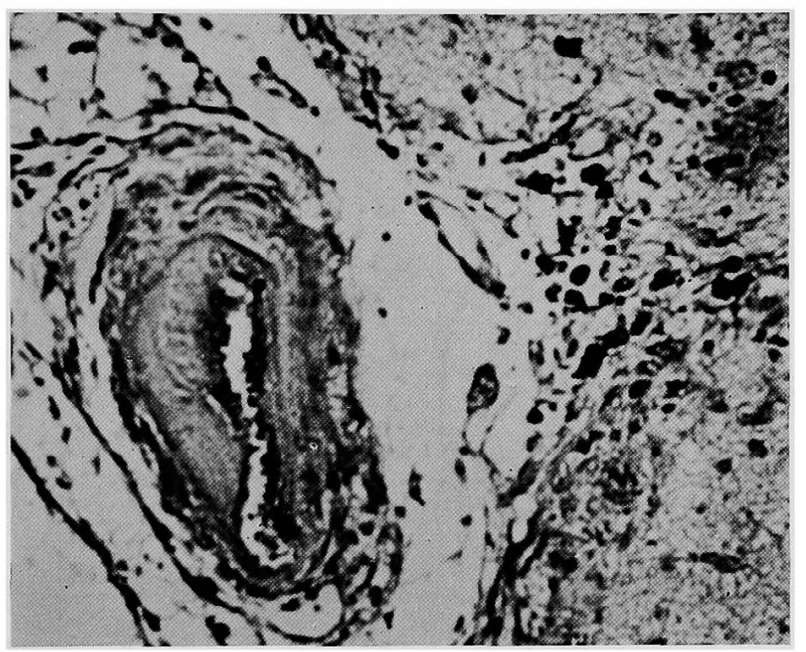

Fig. 6. Fibrinoid necrosis.

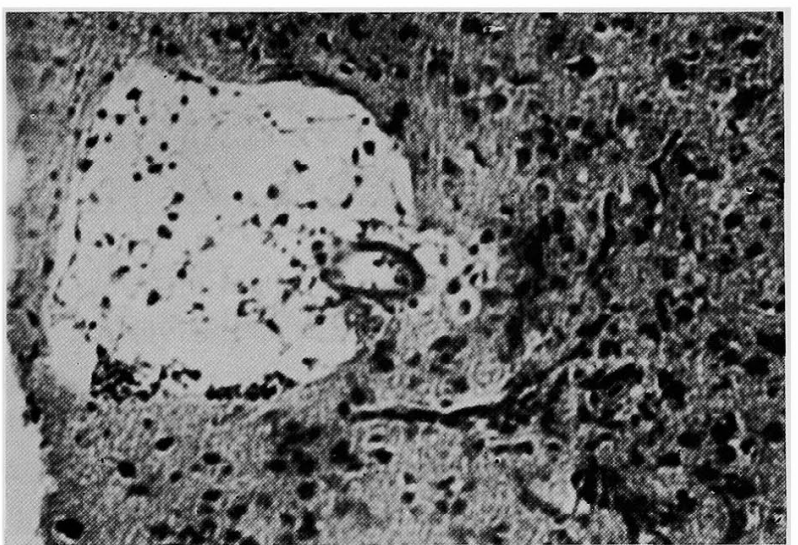

Fig. 7. Cerebral softening.

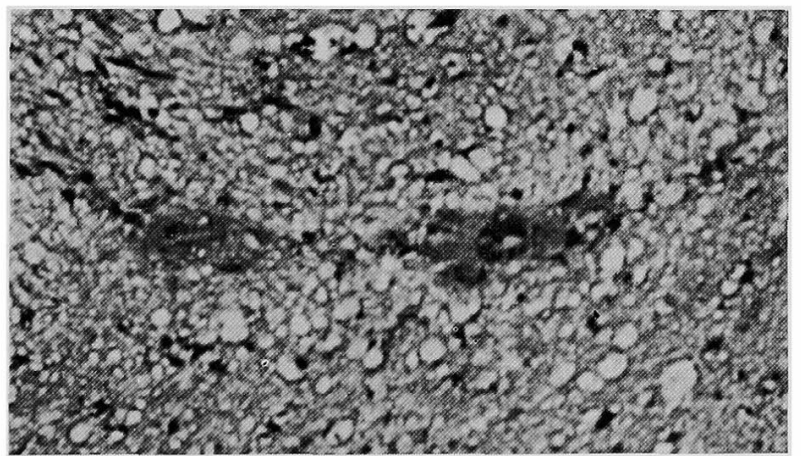

Fig. 8. Plasmatic imbibition. 


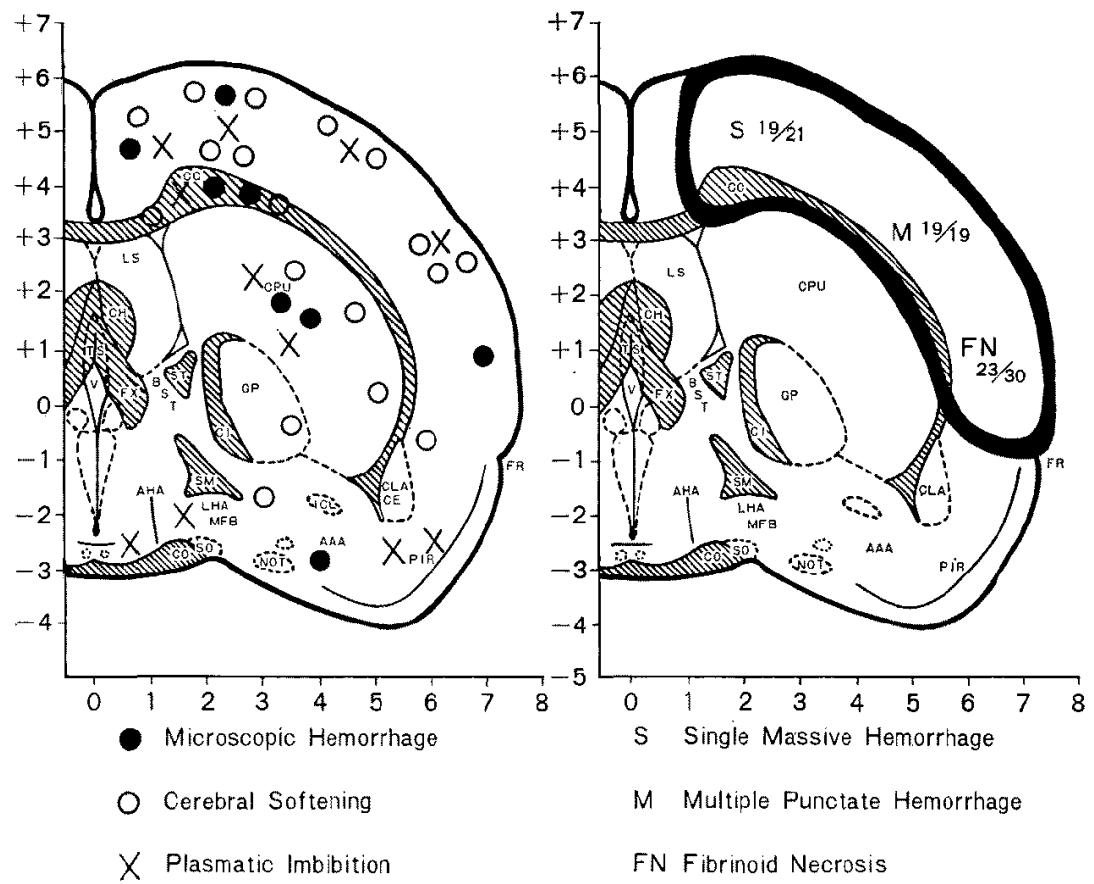

Fig. 9. Localizations of the lesions.

vessel. Perivascular fibrosis or cellular infiltration was rarely seen. The authors could not identify the ruptured part of the vessels even in the serial sections, although aneurysmal dilatation of the vessels was occasionally recognizable.

(5) Cerebral softening (Fig. 7)

This is characterized by local sparseness of cellular integrity and cyst formation of the brain substance due to vacuolization of not only the perivascular space but also the brain parenchym itself. Histologically, falling off of the nerve cells, increase of microglia, severe stenosis of smallest vessel and neovascularization were noted in the cortical-subcortical area in $70 \%$ and also in basal ganglia in $30 \%$.

(6) Plasmatic imbibition (Fig. 8)

In this lesion, presence of PAS positive material around the small vessels of approximately $10 \mu$. in diameter was noted in $65 \%$ cortical-subcortically and $35 \%$ in basal ganglia.

VI. Localization of the lesions (Fig. 9)

Among the above-mentioned 6 different lesions, single massive cerebral hemorrhage, multiple punctate hemorrhage and fibrinoid necrosis were noted almost exclusively in the cortical-subcortial area, while $30-40 \%$ of the micro- 
Table VI. Comparison of the Frequencies of the Lesions Among Groups

\begin{tabular}{|c|c|c|c|c|c|c|}
\hline & 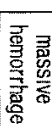 & 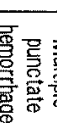 & 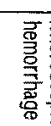 & $\begin{array}{l}\vec{\nabla} \\
\frac{\vec{\rho}}{8} \\
\frac{8}{\omega} \\
\frac{0}{\omega}\end{array}$ & 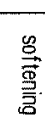 & $\begin{array}{l}\overline{\bar{z}} \\
\overline{\bar{g}} \\
\overline{\mathrm{g}}\end{array}$ \\
\hline \multirow{2}{*}{$\begin{array}{c}\text { Group } \\
1\end{array}$} & $\%$ & & & & & \\
\hline & 0 & 2 & 32 & 4 & 28 & 40 \\
\hline 2 & 2 & 2 & 39 & 3 & 18 & 42 \\
\hline \multirow[t]{2}{*}{3} & & & & & & \\
\hline & 42 & 28 & 20 & 51 & 51 & 27 \\
\hline 4 & 0 & 0 & 40 & 10 & 10 & 40 \\
\hline 5 & 28 & 21 & 20 & 43 & 43 & 28 \\
\hline \multirow[t]{2}{*}{6} & & & & & & \\
\hline & 0 & 13 & 50 & 25 & 50 & 50 \\
\hline 7 & & 28 & 50 & 50 & 50 & 25 \\
\hline
\end{tabular}

scopic hemorrhage, cerebral softening and plasmatic imbibition were found in the basal ganglia.

VII. Comparison of the lesions among groups (Table VI)

There were no macroscopic hemorrhage or fibrinoid necrosis in groups 1,2 and 4, but microscopic hemorrhage, plasmatic imbibition and cerebral softening were rather frequently observed in these groups. In groups 3 and 5 , more single massive hemorrhage $(43 \%, 28 \%)$ than multiple punctate hemorrhage $(28 \%, 21 \%)$ and frequent occurrences of fibrinoid necrosis and cerebral softening were noted, but microscopic hemorrhage or plasmatic imbibition was relatively rare. On the other hand, groups 6 and 7 demonstrated more multiple punctate cerebral hemorrhages than single massive hemorrhage and about half of the group 7 showed fibrinoid necrosis, cerebral softening and microscopic hemorrhage.

VIII. Change of blood pressure and occurrence of lesions

To evaluate the effect of elevation patterns of blood pressure on the development of cerebrovascular lesion, time course of the frequency of the lesions of group 2 (as a representative of moderate hypertensive groups) and group 3 (as a representative of severe hypertensive groups) was depicted (Fig. 


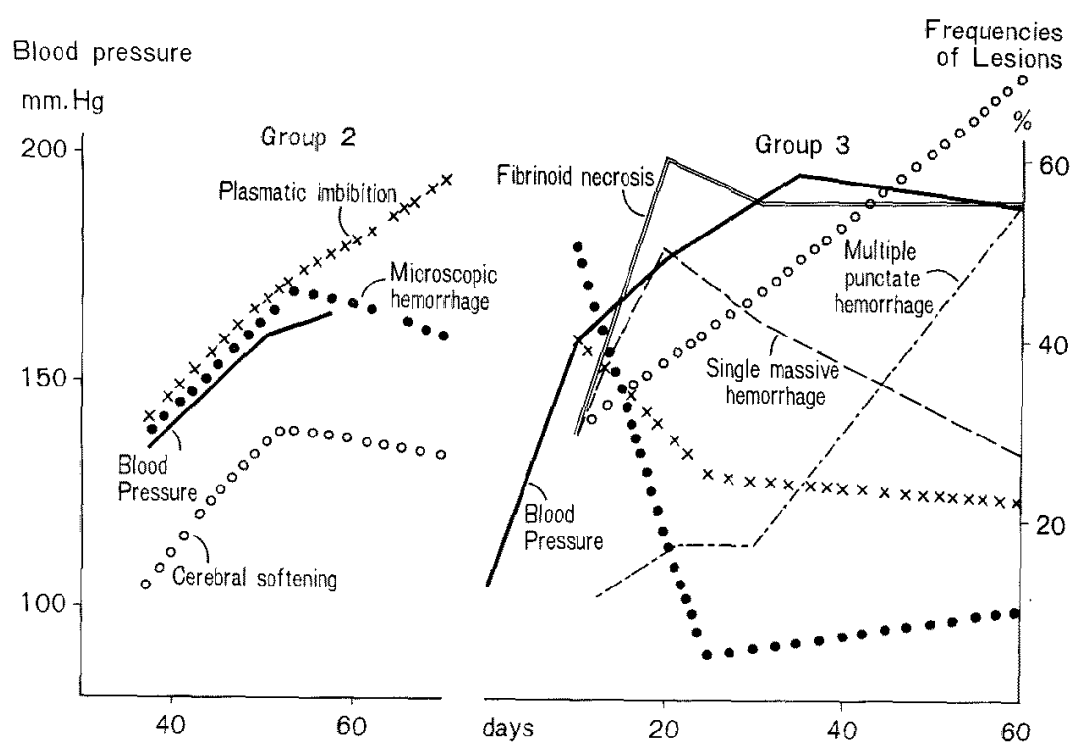

Fig. 10. Change of blood pressure and occurrence of the lesions.

10). As the blood pressure rises in group 2, microscopic hemorrhage and plasmatic imbibition appear more frequently. These, however, decrease abruptly when blood pressure rises higher in group 3, while cerebral softening and punctate multiple hemorrhages become more and more frequent. Massive cerebral hemorrhage and fibrinoid necrosis did not appear in group 2 and appeared at their peak in the early stage of experiment of group 3 when blood pressure elevation was most steep.

\section{Discussion}

Since the accidental observation in experimental renal hypertensive dogs by Goldblatt, ${ }^{7)}$ experimental cerebrovascular lesions have been reported supplementally except for the works of Oshima, ${ }^{211}$ Byrom, ${ }^{31}$ Kameyama' and Oneda. ${ }^{16}$ This is probably due to the infrequency of examining the cerebral vessels and also due to rather infrequent occurrence of cerebrovascular lesions in the usual degree of experimental hypertension. On the other hand, experimental hypertension and vascular lesions have been investigated in the mesenteric, renal or coronary vessels of rats, rabbits and dogs extensively by such methods as constriction of renal artery, ${ }^{21,3), 61,7), 91,11), 15), 16), 18)}$ nephrectomy, ${ }^{14)}$ giving desoxycorticosterone acetate+salt ${ }^{17,22)}$ or pressor substances. ${ }^{22), 19)}$ The causality of the two are variously regarded as follows : hypertension is essential for the development of angionecrosis $;^{21,181}$ hypertension is an 
aggravating but not necessarily a causative factor $;^{14)}$ renal insufficiency is essential ; ${ }^{7)}$ both are not enough ; ${ }^{4}$ hypertension and angionecrosis are rather independent and the latter of which is caused by some angiotoxic substances $; 1,6), 16,15), 19), 20$ ) renin-angiotensin-aldosterone system is involved. ${ }^{12}$, This would result from the differences of species of experimental animals, operative procedures, evaluation of vascular lesions, exactness and/or frequency of measuring blood pressure, etc.

Rats were used in this experiment since a large number of animals can be treated and more frequent and precise measurement of blood pressure is obtainable in this species. This is very important because analyses of the results from the standpoint of not only individual specificity but also group specificity determined by the operative procedures become possible.

As seen in Tables I and IV, elevation patterns of blood pressure differ according to the degree of constriction and/or contralateral renal intervention. When loosely constricted, the rate of increase and degree of maximum of blood pressure were both low, while moderate constriction caused both a high rate of increase and a high degree of maximal blood pressure. Rats with severe constriction died soon after nephrectomy due to uremia. Rats with contralateral renal infarction became markedly hypertensive although the rate of increase was low. From Tables IV and VI, groups with high incidences of fibrinoid necrosis and multiple punctate hemorrhages showed high maximal blood pressure and groups with high incidence of single massive cerebral hemorrhage showed not only high maximal blood pressure but also a high rate of increase in blood pressure. On the other hand, microscopic hemorrhage, brain softening and plasmatic imbibition were frequently seen in the group with less marked hypertension.

Kameyama9) denied positive correlation between high blood pressure and development of fibrinoid necrosis, since hypertension was marked in the loosely constricted group, massive cerebral hemorrhage in the moderately constricted group and fibrinoid necrosis was frequently observed regardless of the degree of constriction in rabbits. Wilson and Pickering, ${ }^{18)}$ however, did not see fibrinoid necrosis in rabbits with elevation of blood pressure by less than $40 \mathrm{~mm} . \mathrm{Hg}$. Absence of fibrinoid necrosis in the clamped kidney was thought to be due to a decrease of perfusion pressure beyond constriction and was thought to indicate that the lesions were not due to a circulatory toxin. Although there are some investigators who postulate or even report isolation ${ }^{20)}$ of renal or humoral factors to cause fibrinoid necrosis, the authors do not see fibrinoid necrosis of cerebral arterioles in the rat groups of lesser degree of hypertension in the 10 weeks of experiment. Therefore, it was felt not necessary for them to postulate the humoral factor, independently of mechani- 
cal factor, in the experiment.

As seen in Fig. 11, fibrinoid necrosis did show its peak appearance in the early stage of the experiment (11 days after constriction) of severely hypertensive groups and rather subsided later on. Keeping pace with fibrinoid necrosis, single massive cerebral hemorrhage became most frequent in appearance around this particular time of experiment. In most of the single massive cerebral hemorrhage, fibrinoid necrosis coexisted. Localization of these 2 lesions was similar (Fig. 9). All these facts seem to point to a close relationship with each other. In the human body, localization of fibrinoid necrosis and massive cerebral hemorrhage is similar to but differs from that of rats. The cause is not clear but may be related to the fact that retrograde branching") of " apoplectic vessels" is not apparent in rats.

Rats which developed cerebral edema and multiple punctate hemorrhages resemble clinico-pathologically the "hypertensive encephalopathy rats" of Byrom. ${ }^{3)}$ His rats reportedly were irritable to outer stimuli and indicated fluctuation of blood pressure, increased permeability of cerebral vessels to trypan blue, cerebral edema, hemorrhage, infarction and arterial necrosis. In our experiment, these rats showed cerebral softening in all cases and fibrinoid necrosis in only $36 \%$. This is exactly reverse to the incidences in rats with single massive cerebral hemorrhage.

Cerebral softening appears even in the mild hypertensive group and is associated with severe stenotic lesions of the vessels which are fairly smaller than those of fibrinoid necrosis. Hemorrhagic complication of softening was noted only in the groups of severe hypertension. This coincides with the report of Matsuoka ${ }^{13)}$ that development of brown softening in human brains is invariably associated with fibrinoid necrosis.

Microscopic hemorrhage and plasmatic imbibition became most frequent in appearance around $150-160 \mathrm{~mm} . \mathrm{Hg}$ of blood pressure and usually carried apparently normal looking small vessels within the stretch. Katsura ${ }^{11)}$ reported similar change in rabbits. Pathogenetical significance of plasmatic imbibition is not clear at present but the lesion seems to be substantially different from fibrinoid necrosis because of the differences in localization, prognosis and relation to the elevation patterns of blood prcssure.

It is very important to take into account the "time factor" in analyzing most biological problems. This is no exception in the case of cerebrovascular lesions of experimental hypertension, since the results would change according to whether the rate of increase of blood pressure is high or low even if maximal blood pressure is the same. Taking into account the "time factor", the authors could classify six different cerebrovascular lesions with corresponding clinical characteristics respectively as follows: microscopic hemorrhage and 
plasmatic imbibition, which are conspicuous in the slight degree of hypertensive period and prognostically good; fibrinoid necrosis and single massive cerebral hemorrhage, which had their peak appearances in the early stage of severe hypertensive group when the rate of increase of blood pressure was maximum and are usually found dead unexpectedly; and cerebral softening and multiple punctate hemorrhage, which are the more frequent in appearances as the blood pressure rises higher and characterized by transient appearance of hyperirritability and by rather poor prognosis.

It was concluded that the massive cerebral hemorrhage in Goldblatt type hypertensive rats, which were associated with steep rising high blood pressure and fibrinoid necrosis, was different pathogenetically from the multiple punctate cerebral hemorrhage, which was associated with brain softening and less steep rising but high blood pressure, and also different from the microscopic hemorrhage associated with moderate increase of blood pressure and plasmatic imbibition.

\section{REFERENCES}

1. Ascher, A. W. and Anson, S. G. : Nature 198: 1097, 1963.

2. Byrom, F. B. and Dodson, L. F.: J. Path. Bact. $60: 357,1948$.

3. Byrom, F. B.: Lancet. ii : 201, 1954.

4. Fleming, H. A.: J. Path. Bact, 65 : 441, 1953.

5. Friedman, M. and Freed, S. C.: Proc. Soc. Exp. Biol. Med. 70 : 670, 1949.

6. Fujii, J.: Jap. Girculat. J. 21 : 653, 1958.

7. Goldblatt, H. : J. Exp. Med. 67: 809, 1938.

8. De Groot, J.: N. V. Noord-Hollandsche Uitgevers Maatschappij, Amsterdam, 1959.

9. Kameyama, M. : Jap. Circulat. J. 21 : 641, 1958.

10. Katsuki, S., Uramoto, T., Motosato, Y., Motosato, Y., and Moriyama E.: Igaku Kenkyu 26: 3049,1956 (in Japanese).

11. Katsura, E. : Nagasaki Med. J. 32 : 1138, 1957 (in Japanese).

12. Masson, G. M. G., Kashii, G., Matsunaga, M., and Page, I. H.: Circulat. Res. 18: 219, 1966.

13. Matsuoka, S. : Jap. Circulat. J. $30: 590,1940$.

14. Muirhead, E. E., Stirman, J. A., Jones, F., Lesch, W., Burns, M., and Fogelman, M. J. : Arch. Int. Med. 91 ; 250, 1953.

15. Murakami, M., Okamoto, H., Yasuda, Y., Masuda, S., Motoda, A., Ikejima, T., Ooka, T., Nagai, T., Yasumura, A., Sanada, I., and Seo, M.: Saishin Igaku 20: 873, 1965 (in Japanese).

16. Oneda, G., Yoshida, Y., Matsuyama, K., Takatama, N., Takeda, F., Oyama, Y., Sudo, H., Sekiguchi, M., and Murata, S. : ibid. 16:2413, 1961 (in Japanese).

17. Selye, H., Beland, E., and Sylvester, O.: Exp. Med. Surg. 2: 224, 1944.

18. Wilson C. and Pickering, G. W.: Clin. Sci. 3: 343, 1938.

19. Winternitz, M. C., Mylon, E., Waters, L. L., and Katzenstein, R. : Yale J. Biol. Med. 12 : $623,1940$.

20. Yamaguchi, H.: Jap. Circulat. J. 30: 1623, 1966.

21. Oshima, K.: Nihon Rinsho 10: 897, 1952 (in Japanese).

22. Ueda, H., Nishimura, H., and Yasuda, H. : Jap. Heart J. 8 : 42, 1957. 